\title{
AS INFLUÊNCIAS DA GOVERNANÇA CORPORATIVA E DA ESTRUTURA DE CAPITAL NO DESEMPENHO E NO RISCO DA FIRMA
}

\section{ON THE INFLUENCES OF CORPORATE GOVERNANCE AND CAPITAL STRUCTURE OVER FIRM PERFORMANCE AND RISK}

\section{SOBRE LAS INFLUENCIAS DEL GOBIERNO CORPORATIVO Y LA ESTRUCTURA DE CAPITAL SOBRE EL DESEMPEÑO Y EL RIESGO DE LA EMPRESA}

\author{
Alexandre Teixeira Dias, Dr. \\ Doutor em Administração pela Faculdade de Ciências Econômicas da Universidade Federal de Minas \\ Gerais. Professor e pesquisador do Programa de Mestrado e Doutorado em Administração da \\ Universidade FUMEC (Brasil) \\ alexandre.tdias@fumec.br \\ http://orcid.org/0000-0002-0512-9829 \\ Willian Douglas Silva, Me. \\ Mestre, pelo Programa de Mestrado e Doutorado em Administração da Universidade Fumec. \\ williandias14@yahoo.com.br \\ http://orcid.org/0000-0003-3004-3821 \\ Jersone Tasso Moreira Silva, Dr. \\ Professor do curso de graduação em Administração e Professor e pesquisador do Programa de \\ Mestrado e Doutorado em Administração da Universidade FUMEC (Brasil). \\ tasso@fumec.br \\ http://orcid.org/0000-0002-9977-9207 \\ Bruno Perez Ferreira, Dr. \\ Professor do Programa de Mestrado e Doutorado em Administração da Universidade Federal de Minas \\ Gerais \\ brunoperez.bh@gmail.com \\ http://orcid.org/0000-0002-1011-5253
}

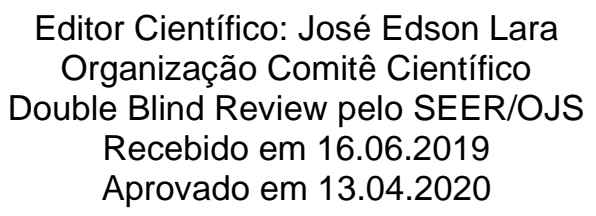




\title{
Resumo
}

Objetivo do estudo: analisar a influência da utilização das melhores práticas de governança corporativa e da estrutura de capital sobre o desempenho e o risco de firmas de capital aberto.

Metodologia/abordagem: abordagem quantitativa, com aplicação de análise de regressão múltipla linear e não-linear.

Originalidade/relevância: esta pesquisa contribui para o preenchimento, ainda que parcial, da lacuna teórica originada nas divergências de resultados entre pesquisas sobre a influência da estrutura de capital e da utilização das melhores práticas de governança corporativa, no desempenho e no risco de firmas de capital aberto.

Principais resultados: identificou-se que o incremento na adoção de boas práticas de governança apresentará efeitos positivos no desempenho, caso os níveis de endividamento sejam mantidos em níveis mínimos, implicando na maior utilização de capital próprio. Quanto ao risco, o incremento na adoção de boas práticas de governança apresenta papel redutor, ao passo que a estrutura de capital de curto prazo apresenta influência incremental, destaque para o efeito quadrático positivo do endividamento total.

Contribuições teóricas/metodológicas: este estudo contribui ao tratar a estrutura de capital como variável explicativa do desempenho, diferentemente de estudos anteriores, que retratam o desempenho como variável preditora da estrutura de capital; ao analisar os dados em uma nova série temporal de 2009 a 2017; ao mensurar os efeitos das boas práticas de governança corporativa no desempenho e no risco das firmas e; ao realizar o desenvolvimento do modelo de regressão múltipla para as análises, com a utilização da variável explicativa endividamento total em termos simples e quadrático.

Palavras-chave: Estrutura de capital, governança corporativa, desempenho, risco.

\begin{abstract}
Objective of the study: to analyze the influence of the use of best corporate governance practices and capital structure on the performance and risk of publicly traded firms.
\end{abstract}

Methodology/approach: quantitative approach, with application of linear and nonlinear multiple regression analysis.

Originality/relevance: this research contributes to the filling, albeit partial, of the theoretical gap originated in the divergences of results between research on the influence of the capital structure and the use of the best corporate governance practices, on the performance and risk of publicly traded firms..

Main results: identified the increase in the adoption of good governance practices will have positive effects on performance if debt levels are kept at minimum levels, implying greater use of equity. As for risk, the increase in the adoption of good governance practices plays a 
reductive role, while the short-term capital structure has incremental influence, highlighting the positive quadratic effect of total indebtedness.

Theoretical/methodological contributions: this study contributes by treating the capital structure as an explanatory variable of performance, unlike previous studies, which portray performance as a predictor variable of the capital structure; when analyzing the data in a new time series from 2009 to 2017; by measuring the effects of good corporate governance practices on the performance and risk of firms and; by performing the development of the multiple regression model for the analyses, using the explanatory variable total indebtedness in simple and quadratic terms.

Keywords: Capital structure, corporate governance, performance, risk.

\section{Resumén}

Objetivo del estudio: analizar la influencia del uso de las mejores prácticas de gobierno corporativo y la estructura de capital en el desempeño y riesgo de las empresas que cotizan en bolsa.

Metodología/enfoque: enfoque cuantitativo, con aplicación de análisis de regresión múltiple lineal y no lineal.

Originalidad/relevancia: esta investigación contribuye al llenado, aunque parcial, de la brecha teórica originada en las divergencias de resultados entre la investigación sobre la influencia de la estructura de capital y el uso de las mejores prácticas de gobierno corporativo, en el desempeño y riesgo de las empresas que cotizan en bolsa.

Principales resultados: reconocido el aumento en la adopción de buenas prácticas de gobernanza tendrá efectos positivos en el rendimiento si los niveles de deuda se mantienen en niveles mínimos, lo que implica un mayor uso de la equidad. En cuanto al riesgo, el aumento de la adopción de buenas prácticas de gobernanza desempeña un papel reductor, mientras que la estructura de capital a corto plazo tiene una influencia incremental, destacando el efecto cuadrático positivo del endeudamiento total.

Contribuciones teóricas/metodológicas: este estudio contribuye al tratar la estructura de capital como una variable explicativa de rendimiento, a diferencia de estudios anteriores, estudios que representan el rendimiento como una variable predictora de la estructura de capital; al analizar los datos en una nueva serie temporal de 2009 a 2017; midiendo los efectos de las buenas prácticas de gobierno corporativo en el desempeño y el riesgo de las empresas y; realizando el desarrollo del modelo de regresión múltiple para los análisis, utilizando la variable explicativa en deuda total en términos simples y cuadráticos.

Palabras clave: Estructura de capital, gobierno corporativo, rendimiento, riesgo.

\section{Introdução}

A teoria Static Trade-Off estabelece a existência de uma estrutura ótima de capital que maximize o valor da firma. Já a Pecking Order Theory pressupõe a preferência das fontes de financiamento de forma hierárquica como mecanismo de sinalização ao mercado sobre a 
situação financeira da firma (Myers \& Majluf, 1984). A estrutura ótima de capital que maximizará o desempenho e o valor da firma ocorrerá quando ela alcançar o equilíbrio entre os benefícios fiscais, proporcionados pela emissão da dívida, e o aumento dos custos de falência decorrentes da captação de recursos de terceiros (Leites \& Zani, 2008; Medeiros \& Daher, 2008).

Os investidores, ao se sentirem protegidos dada a redução do risco de perda dos investimentos, podem conceder financiamentos a taxas menores, com maior prazo de vencimento e em maiores quantidades, possibilitando assim à firma aproveitar todos os benefícios do endividamento, além de poder investir em mais projetos rentáveis, consequentemente influenciando positivamente a rentabilidade e o desempenho no mercado de capitais (Koerniadi, Krishnamurti, \& Tourani-Rad, 2014).

Pesquisas acadêmicas no Brasil demonstram uma relação negativa entre endividamento e rentabilidade (Silva, Santos, \& Nakamura, 2018). Contudo há outras pesquisas que mostram o contrário, uma associação positiva entre endividamento e rentabilidade (Silva \& Silva, 2017). Essa divergência motiva o desenvolvimento de novas pesquisas no campo das finanças.

Em pesquisa no portal de periódicos da Coordenação de Aperfeiçoamento de Pessoal de Nível Superior (Capes), realizada em agosto de 2017, sobre o assunto "capital structure", obteve-se retorno de 2.358 resultados, o que demonstra a relevância do tema nas pesquisas acadêmicas em finanças e, portanto, justifica a escolha desta pesquisa.

Apesar do grande número de pesquisas empíricas que procuram analisar os efeitos da estrutura de capital sobre o desempenho da firma (Fama \& French, 2012; Frank \& Goyal, 2003; Silva \& Silva, 2017), não se obteve um consenso nessa relação. Os resultados são divergentes: ora há uma relação positiva, ora uma negativa entre endividamento e desempenho, além das pesquisas que apresentam resultados inconclusivos. Assim, a temática "estrutura de capital" constitui uma das mais importantes preocupações relativas ao financiamento corporativo.

Verifica-se ainda que as pesquisas identificadas procuram analisar a influência de alguns fatores sobre a estrutura de capital (Avelar, Cavalcanti, Pereira, \& Boina, 2017; Reis, Campos, \& Pasquini, 2017). Esses estudos abordam principalmente variáveis como tamanho, lucratividade, rentabilidade, tangibilidade dos ativos, geração de caixa antes dos juros, impostos e depreciação, variação e crescimento da lucratividade sobre a estrutura de capital.

O trabalho de Silva e Silva (2017) buscou analisar a relação entre estrutura de capital, crescimento do ativo, lucratividade e valor de mercado de 547 firmas brasileiras listadas na 
[B]3, no período de 2006 a 2015. Para consecução da pesquisa os autores desenvolveram 2 modelos de regressão: o primeiro com lucratividade como variável dependente e as variáveis de estrutura de capital e crescimento do ativo como independentes; e o segundo com o valor de mercado como variável resposta e a lucratividade, crescimento do ativo e estrutura de capital como variáveis explicativas.

Mendes e Santos (2018) verificaram a relação da estrutura de capital com a dinâmica da indústria e o desempenho financeiro, e encontraram uma relação negativa entre todos os níveis de endividamento e o desempenho das firmas, no período de 1994 a 2014, em uma amostra de 995 firmas. Com modelo de análise os autores usaram o modelo de equações estruturais para mensurar a influência da dinâmica da indústria e do desempenho sobre a estrutura de capital.

As divergências de resultados entre algumas das pesquisas já realizadas demonstram uma lacuna aberta para novas pesquisas empíricas sobre a influência da estrutura de capital no desempenho das firmas brasileiras. Neste sentido, este estudo contribui ao tratar a estrutura de capital como variável explicativa do desempenho, diferentemente dos estudos de Avelar, Cavalcanti, Pereira e Boina (2017), Mendes e Santos (2018) e Reis, Campos e Pasquini ( 2017) que retratam o desempenho como variável preditora da estrutura de capital. Contribui, ainda, ao analisar os dados em uma nova série temporal de 2009 a 2017 e ao realizar o desenvolvimento do modelo de regressão múltipla para as análises com a utilização da variável explicativa endividamento total em termos simples e quadrático.

As pesquisas de Araújo, Confessor, Santos, Oliveira e Prazeres (2017), Cicogna, Toneto e Valle (2007) e Ripamonti and Kayo (2016) consideram os níveis de governança corporativa da $[\mathrm{B}] 3$ como medida de boas práticas de governança corporativa. A listagem nos melhores níveis influencia positivamente o desempenho econômico, segundo Almeida, Parente, Luca e Vasconcelos (2018) e Lima, Oliveira, Cabral, Santos e Pessoa (2015); já para Bernardino, Peixoto e Ferreira (2014), esses efeitos são negativos. Há ainda as pesquisas que buscam relacionar o endividamento com os níveis de governança corporativa (Fonseca, Silveira, \& Hiratuka, 2016; Pinheiro, Vasconcelos, Luca, \& Crisóstomo, 2017), pois esse relacionamento tem um efeito positivo no endividamento total e no perfil do endividamento. Já no estudo de Vieira, Velasquez, Losekann e Ceretta (2011), essa relação não foi comprovada estatisticamente.

Considerando o exposto, a presente pesquisa se baseia no fato de que as firmas brasileiras de capital aberto listadas na [B]3, ao adotarem as melhores práticas de governança corporativa, reduzem a assimetria de informações perante o mercado. Assim, possibilitam a 
diminuição dos custos de agência e falência atrelados à utilização de capital de terceiros, o que permite o aumento na quantidade e a melhoria na qualidade do endividamento.

Reafirma-se que a temática relacionada à governança corporativa é constantemente objeto de estudos acadêmicos. Em pesquisa realizada no portal de periódicos da Capes, em de agosto de 2017, sobre o assunto "corporate governance", foram identificados 16.949 resultados, o que evidencia a relevância do tema e também justifica o presente trabalho. Contudo, ao associar os temas estrutura de capital e governança corporativa, é encontrado um número limitado de artigos. Em busca feita no portal de periódico da Capes sobre o assunto "capital structure" e "corporate governance", foram identificados 161 trabalhos. Já quando se aborda a influência da governança corporativa no valor de mercado da firma, Cunha (2017) identificou uma relação positiva, ainda que sutil. Este autor mensurou a governança corporativa com base no índice desenvolvido por Silva and Leal (2005).

Tendo em vista os pontos abordados anteriormente, este trabalho tem como principal objetivo identificar a influência da utilização das melhores práticas de governança corporativa, medidas pelos níveis de governança corporativa da [B]3, e da estrutura de capital, sobre o desempenho e o risco das firmas brasileiras de capital aberto listadas na $[\mathrm{B}] 3$, do setor da indústria manufatureira.

\section{Fundamentação teórica}

\subsection{Estrutura de capital}

Desde o trabalho de Modigliani and Miller (1958) que propuseram a teoria da irrelevância da estrutura de capital para determinação do valor de mercado das firmas, em oposição à teoria tradicional sobre a estrutura de capital, que defendia que as firmas buscavam uma estrutura ótima de capital (Durand, 1952), sugiram diversas pesquisas relacionadas à dinâmica da política de financiamento da firma, seja testando as teorias mais adequadas para explicar a estrutura de capital ou desenvolvendo novas (Avelar et al., 2017; Fama \& French, 2012; Fonseca et al., 2016; Frank \& Goyal, 2003; Koerniadi et al., 2014; Mendes \& Santos, 2018; Myers, 1984; Myers \& Majluf, 1984; Pamplona, Magro, \& Silva, 2017; Reis et al., 2017; Silva et al., 2018; Silva \& Silva, 2017). 


\subsection{Teoria Static Trade-Off}

A teoria Static Trade-Off foi desenvolvida no estudo de Myers (1984), que analisou a estrutura de capital das firmas em relação aos ganhos com o endividamento (benefícios fiscais) em detrimento dos custos de falência (o que inclui também os de transações relacionados às dívidas). Segundo os pressupostos dessa teoria, as firmas se financiariam por meio de capital de terceiros até o momento em que as vantagens fiscais adicionais do endividamento fossem compensadas pela majoração dos possíveis custos de falência de transações financeiras (Myers, 2001). Para o autor, as firmas com melhor desempenho econômico, portanto distantes dos problemas financeiros, tendem a contrair maiores quantidades de capital de terceiros, com o objetivo de aproveitar todos os benefícios fiscais.

Analisando a utilização de capital próprio e de terceiros pelas firmas brasileiras listadas na [B]3, Correia, Silva e Martins (2018) identificaram que, em média, elas têm, em sua estrutura, maior participação de capital de terceiros do que de capital próprio. Também foi observado por esses autores que a utilização de capital de terceiros vem variando em torno da média no período de 2010 a 2014, indicando alinhamento com a teoria Static Trade-Off, pela procura por uma proporção ideal entre o de terceiros e o próprio.

\subsection{Estrutura de capital e desempenho}

As influências da estrutura de capital no desempenho da firma tem sido objeto de estudos que identificam a probabilidade de obtenção de maiores patamares de desempenho por firmas com menor endividamento de longo prazo e por firmas com maior endividamento de curto prazo, a exemplo de Lara e Mesquita (2008).

O efeito da estrutura de capital sobre o desempenho de firmas brasileiras de capital aberto listadas na [B]3 foi abordado por Machado, Prado, Vieira, Antonialli e Santos (2015). Os achados indicaram que as firmas menos endividadas obtiveram desempenho superior às firmas mais alavancadas, demonstrando que as mais rentáveis são as de menores níveis de endividamento, resultado semelhante ao apurado por Pamplona, Magro e Silva (2017), quando estudaram empresas Portuguesas, e por Mendes e Santos (2018) e Silva e Silva (2017). Tais resultados se alinham às Teorias Static Trade-Off e Pecking Order.

Tomando por referência as relações apresentadas anteriormente e os resultados das pesquisas de Artikis and Nifora (2011), Danis, Rettl and Whited (2014), Pamplona et al. (2017) 
e Silva e Silva (2017), este trabalho tem por um de seus objetivos analisar a influência da estrutura de capital no desempenho. Assim, tem-se as seguintes hipóteses:

$\mathrm{H}_{1}$ - Quanto maior o endividamento total da firma, menor será o seu desempenho.

$\mathrm{H}_{1 \mathrm{~B}}$ - Quanto maiores os endividamentos de curto e de longo prazo, menor será o desempenho da firma.

$\mathrm{H}_{1 \mathrm{C}}-\mathrm{O}$ endividamento total da firma exerce influência não-linear no desempenho.

\subsection{Estrutura de capital e risco}

Sobre os debates relativos à estrutura de capital, existem discussões diferenciadas entre as teorias em relação ao risco econômico financeiro da firma e ao risco do mercado de capitais. Pela teoria proposta por Modigliani and Miller (1958 e 1963), observa-se que todos os benefícios da dívida são compensados pelo aumento do risco. Assim, à medida que o capital de terceiros aumenta, as incertezas sobre o resultado da firma e consequentemente o risco aos proprietários também crescem, eliminando, assim, os ganhos para os acionistas (Brealey, Myers, \& Allen, 2007). Na teoria Static Trade-Off, de Myers (1984), é esperada uma relação negativa entre o risco e o endividamento, pois os altos custo de falência e de agência limitariam a tomada de crédito pelas firmas (Fama, \& French, 2012). Já pela teoria Pecking Order, as firmas optariam sempre pelas fontes de financiamento com menor risco, no caso, os lucros acumulados (Myers \& Majluf, 1984).

Em pesquisa empírica, Silveira, Perobelli e Barros (2008) identificaram uma relação negativa entre as dívidas bancárias e de mercado de capitais e a volatilidade dos retornos do ativo total. Corroborando o referido trabalho, Fonseca, Silveira e Hiratuka (2016) verificaram que o desvio padrão do retorno antes de juros e impostos sobre o ativo total é relacionado negativamente com o endividamento de curto prazo das firmas. Em relação ao endividamento total e ao de longo prazo, não se observou significância estatística.

Diante das pesquisas expostas, infere-se que, à medida que a firma aumento seu endividamento, os investidores percebem o aumento dos riscos de falência e do negócio, refletindo em sua avaliação sobre a firma, consequentemente em maiores índices de volatilidade das ações. Assim, esta pesquisa busca averiguar as seguintes hipóteses:

$\mathrm{H}_{2}$ - Quanto maior o endividamento total da firma, maior será o seu risco.

$\mathrm{H}_{2 \mathrm{~B}}$ - Quanto maiores os endividamentos de curto e de longo prazo, maior será o risco da firma. 


$$
\mathrm{H}_{2 \mathrm{C}}-\mathrm{O} \text { endividamento total da firma exerce influência não-linear no risco. }
$$

\subsection{Governança corporativa}

A governança corporativa é conceituada de acordo com Shleifer and Vishny (1997) como a forma que os fornecedores de recursos, próprios ou de terceiros, asseguram que conseguirão para si o retorno sobre o capital investido, por meio dos controles que os dirigentes colocam sobre si mesmos, ou que os fornecedores de recursos aplicam sobre os gestores, com o objetivo de diminuir o emprego errado dos recursos e incentivar os investidores a fornecerem mais recursos à firma.

A [B]3 (2018) estabeleceu seis níveis de segmentos de listagem: básico, nível 1, nível 2, novo mercado, Bovespa mais nível 2, e Bovespa mais, em que o primeiro não exige nenhum tipo de regra de governança corporativa e o novo mercado traz todas as regras contendo as melhores práticas. Os critérios de listagem que medem a qualidade da governança corporativa da [B]3 são baseados em: características das ações emitidas; percentual mínimo de ações em circulação; distribuições públicas de ações; vedação a disposições estatutárias; composição do conselho de administração; vedação a acumulações de cargos; obrigações do conselho de administração; demonstrações financeiras; reunião pública anual, calendários de eventos corporativos; divulgações adicionais de informações; concessão de Tag Along; oferta pública de aquisição de ações no mínimo pelo valor econômico; e adesão à câmara de arbitragem do mercado.

No Brasil as firmas que ingressam nos níveis de governança corporativa da [B]3 são comprometidas com transparência, equidade, prestação de contas e responsabilidade corporativa. Essas práticas são capazes de provocar um maior crescimento do valor de mercado, incrementar o volume de negociações das ações, reduzir o risco, diminuir o custo de capital ponderado ou melhorar o retorno sobre o ativo (Rogers, Securato, \& Ribeiro, 2008).

\subsection{Governança corporativa e desempenho}

O estudo de Catapan e Colauto (2014) tinha o objetivo de avaliar a relação entre governança corporativa e o retorno sobre o patrimônio líquido, o retorno sobre o ativo total e o Q de Tobin, em uma amostra com firmas brasileiras listadas na [B]3, no período entre 2010 e 2012. Os resultados indicaram que as práticas de governança corporativa influenciam o retorno sobre o ativo total e o Q de Tobin. De forma semelhante, Lima et al. (2015) verificaram que as 
firmas brasileiras listadas nos melhores níveis de governança corporativa da [B]3 apresentam variação média do valor de mercado superior aos níveis inferiores, sendo o valor de mercado das firmas listadas no novo mercado superior ao nível 2 e este, por sua vez, superior ao nível 1. Para os autores, a valorização superior das firmas listadas no mais elevado nível de governança corporativa pode ser um incentivo para as demais firmas buscarem ingressar nos melhores níveis.

Almeida et al. (2018) abordaram os efeitos da governança corporativa no desempenho empresarial das firmas brasileiras de engenharia listadas na $[\mathrm{B}] 3$ e identificaram que a governança corporativa influencia positivamente o ROE, o ROA e o valor de mercado (Q de Tobin), resultado semelhante ao encontrado por Cunha (2017), que identificou que a governança corporativa influencia positivamente a taxa de crescimento da lucratividade e o valor de mercado (Q de Tobin).

Diante dessas considerações, em que se evidencia a relação positiva entre o desempenho e os níveis de governança corporativa da [B]3, elabora-se a seguinte hipótese:

$\mathrm{H}_{3}$ - Quanto melhores as práticas de governança corporativa, melhor será o desempenho da firma.

\subsection{Governança corporativa e risco}

Besarria, Paula, Araújo, Alves, Almeida e Monteiro (2015) analisaram se os efeitos da transparência das informações e do crescimento dos direitos societários são capazes de diminuir os riscos dos investidores. Para a operacionalização da pesquisa, os autores construíram três carteiras teóricas: novo mercado, nível 1 e nível 2, e calcularam os betas teóricos dessas carteiras em relação à carteira do índice Ibovespa. Os resultados indicaram que a carteira teórica do novo mercado apresentou um risco inferior à carteira do Índice Bovespa, entendendo-se, então, que as ações listadas no novo mercado incorrem em menor risco. As razões para tais constatações podem ser atreladas aos níveis de transparência das informações, que permitem melhor avaliação, por parte dos investidores, do valor justo dos ativos.

Besarria e Silva (2017) analisaram a efetividade da governança corporativa sobre as ações negociadas na [B]3. Para isso os autores estimaram a composição das carteiras do nível 1, nível 2 e novo mercado e estimaram o beta da carteira, usando as cotações das ações do período de 01 de junho de 2012 a 04 de julho de 2016. Os resultados dessa pesquisa evidenciaram que as carteiras dos mais altos níveis de governança corporativa da [B]3 apresentaram-se menos 
arriscadas. Para os autores, os investidores que buscam ativos menos voláteis devem preferir alocar o capital em firmas com maior transparência.

Os trabalhos citados sugerem que as firmas preocupadas com os investidores e que implementam boas práticas de governança corporativa, como transparência, fidedignidade das informações prestadas e gestão confiável, possibilitam aos investidores avaliá-las com mais precisão quanto ao seu desempenho econômico-financeiro. Dessa forma, verifica-se uma menor volatilidade das ações, refletindo em menores riscos associados aos ativos, o que se pretende verificar neste estudo. Diante das considerações expostas, o presente trabalho busca averiguar a seguinte hipótese:

$\mathrm{H}_{4}$ - Quanto melhores as práticas de governança corporativa da firma, menor será o risco.

\section{Metodologia}

\subsection{Variáveis dos modelos}

As variáveis dependentes consistem nos indicadores que têm a finalidade de mensurar o desempenho no mercado de capitais e a volatilidade das ações. Consideram-se, para tanto, duas variáveis:

QTOBIN - Q de Tobin - é definido como a razão entre o valor de mercado de uma firma e o valor de reposição de seus ativos físicos. Famá e Barros (2000) destacam que devido à dificuldade de cálculo do Q de Tobin original, o cálculo simplificado dado pela razão entre o valor de mercado da firma e o valor do ativo pode ser utilizado, o que foi adotado nesta pesquisa. O Q de Tobin simplificado já foi utilizado nos trabalhos de Gonçalves, Dias, De-Carvalho e Martins (2014), Machado et al. (2015) e Vieira et al. (2011) e descrito como valor da firma.

VOLATIL - volatilidade do retorno das ações - é uma variável adotada como medida de risco das firmas, ou seja, probabilidade de o investidor incorrer em perdas ao adquirir as ações da firma (Malacrida \& Yamamoto, 2006). A volatilidade utilizada é calculada por meio do desvio padrão dos logaritmos neperianos dos retornos diários das firmas, no período de 1 ano (Alves, 2010). Assim, quanto menor esse indicador, menor será a percepção de risco dos investidores no investimento em uma firma.

Este trabalho adota a classificação da governança corporativa da [B]3 e a estrutura de capital, decomposta nos indicadores endividamento total, endividamento de curto prazo e endividamento de longo prazo como variáveis independentes.

ENDTOTAL - Endividamento total (razão entre o passivo circulante somado ao passivo não circulante e o ativo total) representa a quantidade total de ativos fornecidos pelos credores 
à firma (Mendes \& Santos, 2018). Quanto maior esse índice, maior a proporção de capital de terceiros utilizada para gerar lucros para firma. Esse indicador foi aplicado nos trabalhos de Machado et al. (2015) e Mendes e Santos (2018).

ENDC - Endividamento de curto prazo (razão entre o passivo e o ativo) significa o total de ativos fornecidos pelos credores e que serão exigidos por estes até o fim do encerramento do exercício social seguinte (Martins, Gelbeke, Santos, \& Iudícibus, 2013). Quanto menor esse indicador, menores serão os riscos de falência da firma e maior a liberdade de decisões de investimento pelo administrador. Indicador já utilizado nos trabalhos de Avelar et al. (2017), Correia et al. (2018) e Machado et al. (2015).

ENDL - Endividamento de longo prazo (razão entre passivo não circulante e o ativo total) representa os ativos totais financiados pelo capital de terceiros, que serão exigidos pelos credores após o encerramento do exercício social seguinte ao balanço patrimonial atual (Martins et al., 2013).

GC - Governança Corporativa é uma variável categórica (dummy), que representa a classificação da governança corporativa pela [B]3, de acordo com os segmentos de listagem. A variável recebe a classificação um nos anos em que a firma estava inserida em um dos três segmentos de governança corporativa: nível 1, nível 2 e novo mercado; e zero nos anos em que a firma esteve listada no nível tradicional da [B]3, procedimento adotado por Cicogna et al. (2007) e Fonseca et al. (2016).

\subsection{Amostra e coleta de dados}

A amostra da pesquisa compreende as informações das firmas brasileiras listadas na [B]3 e com ações negociadas, atuantes na indústria manufatureira, e abrange os anos de 2009 a 2015. A escolha dessa indústria é justificada por três pontos: a) A análise da relação do endividamento e desempenho deve considerar o ambiente de atuação das firmas e a natureza estrutural da organização da indústria (Gonçalves et al., 2014); b) A indústria manufatureira é composta por firmas de uso de capital intensivo, tais como em fábricas, maquinário e estoque na indústria. De acordo com Louzada, Oliveira, Silva e Gonçalves (2016), as indústrias manufatureiras demandam grandes volumes de ativos fixos, de máquinas para produção mecanizada em grande escala e trabalham com elevado endividamento; c) A maior parcela das firmas listadas nos segmentos de governança corporativa ou no mercado tradicional da [B]3 atuam na indústria manufatureira. 
Quanto à escolha do período entre 2009 e 2015, ela se deu em razão de se optar por excluir das análises os efeitos da crise internacional do subprime, a partir de 2009, e por acessibilidade dos dados até o ano de 2015. Foram coletadas informações de 94 firmas ativas da indústria manufatureira, das quais 43 listadas no mercado tradicional e 51 em segmento de governança corporativa da $[\mathrm{B}] 3$, totalizando 613 casos.

\subsection{Método de análise dos dados}

As análises dos modelos de regressão múltipla foram realizadas com o auxílio do Software Minitab 18. Para analisar os efeitos da governança corporativa e da estrutura de capital sobre os desempenhos econômico e do mercado de capitais e sobre o risco, foi utilizada a técnica estatística de regressão linear múltipla do tipo corte transversal. Os modelos de regressão múltipla foram desenvolvidos com a utilização de variáveis dummy para os níveis de governança corporativa, considerando o Nível Básico como categoria base. Foi empregado nas regressões o procedimento de estimação de mínimos quadrados ordinários.

Considerando as hipóteses propostas para esta pesquisa, os modelos de regressão múltipla foram desenhados para cada uma das variáveis dependentes, com o objetivo de mensurar o percentual de variância que é explicado pelas variáveis explicativas endividamento total, endividamento total em sua forma quadrática, endividamento de curto prazo e de longo prazo e governança corporativa - Tabela 1 .

Tabela 1. Modelos de regressões

\begin{tabular}{|c|c|c|c|}
\hline $\begin{array}{l}\text { VARIÁVEL } \\
\text { DEPENDENTE }\end{array}$ & MODELO & EQUAÇÃO & HIPÓTESES \\
\hline \multirow{3}{*}{ QTOBIN } & QTOBIN $=\alpha+\beta_{1}$ ENDTOTAL $+\beta_{2} \mathrm{GC}+\varepsilon$ & $(1)$ & $\mathrm{H}_{1} ; \mathrm{H}_{3}$ \\
\hline & QTOBIN $=\alpha+\beta_{1}$ ENDC $+\beta_{2}$ ENDL $+\beta_{3} \mathrm{GC}+\varepsilon$ & (2) & $\mathrm{H}_{1 \mathrm{~B}} ; \mathrm{H}_{3}$ \\
\hline & $\begin{array}{c}\text { QTOBIN }=\alpha+\beta_{1}{\text { ENDTOTAL }+\beta_{2} \text { ENDTOTAL }^{2}}+\beta_{3} \mathrm{GC}+\varepsilon\end{array}$ & (3) & $\mathrm{H}_{1 \mathrm{C}} ; \mathrm{H}_{3}$ \\
\hline \multirow{3}{*}{ VOLATIL } & VOLATIL $=\alpha+\beta_{1}$ ENDTOTAL $+\beta_{2} \mathrm{GC}+\varepsilon$ & $(4)$ & $\mathrm{H}_{2} ; \mathrm{H}_{4}$ \\
\hline & VOLATIL $=\alpha+\beta_{1}$ ENDC $+\beta_{2}$ ENDL $+\beta_{3}$ GC $+\varepsilon$ & $(5)$ & $\mathrm{H}_{2 \mathrm{~B}} ; \mathrm{H}_{4}$ \\
\hline & 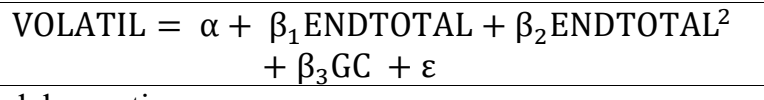 & $(6)$ & $\mathrm{H}_{2 \mathrm{C}} ; \mathrm{H}_{4}$ \\
\hline
\end{tabular}

$\alpha=$ Constante do modelo a estimar;

$\beta_{1}, \beta_{2}$ e $\beta_{3}=$ Coeficientes de regressão a estimar;

$\varepsilon=$ Resíduo do modelo.

* significância a 10\%, ** significância a 5\% e *** significância a $1 \%$.

Fonte: Elaborado pelos autores 


\section{Resultados}

\subsection{Variável dependente QTOBIN}

Na Tabela 2 são apresentados os resultados da estimação dos parâmetros do modelo da equação (1), com as variáveis endividamento total (ENDTOTAL) e governança corporativa (GC) como explicativas do desempenho no mercado de capitais (Q de Tobin). O ENDTOTAL apresentou efeito negativo e significativo $(\mathrm{p}<0,010)$ no $\mathrm{Q}$ de Tobin, permitindo afirmar que quanto maior o ENDTOTAL, menor o desempenho, resultado que leva à não rejeição da Hipótese 1. O modelo apresentou capacidade explicativa de 17,64\%. Quanto aos níveis de governança (GC), seu efeito no desempenho apresentou-se positivo e estatisticamente significativo ( $<$ 0,010), levando à não rejeição da Hipótese 3, para os três modelos.

Tabela 2 1Ajuste dos modelos para a variável Q de Tobin.

\begin{tabular}{|c|c|c|c|c|c|c|c|c|}
\hline EQUAÇÃO & VARIÁVEIS & COEFICIENTE & $\begin{array}{c}\text { ERRO } \\
\text { PADRÃOO }\end{array}$ & TESTE $T$ & $\begin{array}{c}\text { P- } \\
\text { VALOR }\end{array}$ & VIF & RELAÇÃO & SIG \\
\hline \multirow{3}{*}{1} & $\begin{array}{l}\text { Constante } \\
\text { ENDTOTAL } \\
\text { GC }\end{array}$ & $\begin{array}{c}1,47 \\
-1,55 \\
0,27\end{array}$ & $\begin{array}{l}0,10 \\
0,15 \\
0,06\end{array}$ & $\begin{array}{c}15,48 \\
-10,42 \\
4,32\end{array}$ & $\begin{array}{l}0,000 \\
0,000 \\
0,000\end{array}$ & $\begin{array}{l}1,00 \\
1,00\end{array}$ & $\begin{array}{l}+ \\
- \\
+\end{array}$ & $\begin{array}{l}* * * \\
* * * \\
* * *\end{array}$ \\
\hline & $\begin{array}{l}\mathrm{R}^{2} \\
\mathrm{~F}(2,568)\end{array}$ & \multicolumn{2}{|c|}{$\begin{array}{c}17,93 \% \\
61,84\end{array}$} & & \multicolumn{2}{|c|}{$\begin{array}{l}\mathrm{R}^{2} \text {-Ajustado } \\
\text { P-Valor (F) }\end{array}$} & \multicolumn{2}{|l|}{$\begin{array}{c}17,64 \% \\
0.000\end{array}$} \\
\hline & Durbin Watson & \multicolumn{2}{|c|}{0,466951} & KS & 0,145 & -Valor & $<0,010$ & \\
\hline \multirow{6}{*}{2} & Constante & 1,43 & 0,10 & 14,89 & 0,000 & & + & **** \\
\hline & ENDC & $-1,13$ & 0,21 & $-5,44$ & 0,000 & 1,04 & - & $* * *$ \\
\hline & ENDL & $-1,85$ & 0,18 & $-10,17$ & 0,000 & 1,05 & - & $* * *$ \\
\hline & $\mathrm{GC}$ & 0,30 & 0,06 & 4,77 & 0,000 & 1,03 & + & $* * *$ \\
\hline & $\begin{array}{l}\mathrm{R}^{2} \\
\mathrm{~F}(3,568)\end{array}$ & \multicolumn{2}{|c|}{$19,08 \%$} & & \multicolumn{2}{|c|}{$\mathrm{R}^{2}$-Ajustado } & \multicolumn{2}{|l|}{$18,65 \%$} \\
\hline & Durbin Watson & \multicolumn{2}{|c|}{0,477943} & KS & \multicolumn{2}{|c|}{$\begin{array}{c}\text { P-Valor (F) } \\
0,147 \quad \text { P-Valor } \\
(\mathrm{KS})\end{array}$} & $<0,010$ & \\
\hline \multirow{7}{*}{3} & Constante & 1,41 & 0,17 & 8,08 & 0,000 & & + & **** \\
\hline & ENDTOTAL & $-1,26$ & 0,66 & $-1,90$ & 0,058 & 19,71 & - & $*$ \\
\hline & ENDTOTAL $^{2}$ & $-0,27$ & 0,59 & $-0,46$ & 0,648 & 19,68 & - & \\
\hline & $\mathrm{GC}$ & 0,27 & 0,06 & 4,21 & 0,000 & 1,02 & + & $* * *$ \\
\hline & $\mathrm{R}^{2}$ & 17,96 & & & \multicolumn{2}{|c|}{$\mathrm{R}^{2}$-Ajustado } & \multicolumn{2}{|l|}{$17,53 \%$} \\
\hline & $F(3,568)$ & \multicolumn{2}{|c|}{41,24} & & \multicolumn{2}{|c|}{ P-Valor (F) } & \multicolumn{2}{|l|}{0,000} \\
\hline & Durbin Watson & \multicolumn{2}{|c|}{0,467599} & KS & \multicolumn{2}{|c|}{ 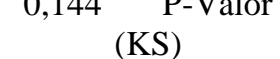 } & $<0,010$ & \\
\hline
\end{tabular}

* significância a 10\%, ** significância a 5\% e *** significância a 1\%.

As variáveis ENDC e ENDL foram utilizadas como variáveis independentes no modelo da equação (2), relativo à explicação da variação no Q de Tobin, mensurada em 18,65\%. Conforme pode ser constatado na Tabela 2, os indicadores ENDC e ENDL apresentam efeito negativo e estatisticamente significativo no $Q$ de Tobin $(p<0,010)$. Dessa forma, à medida que 
o endividamento aumenta, o desempenho se reduz, resultado que leva à não rejeição da Hipótese 1B.

A variável ENDTOTAL foi utilizada no modelo da equação (3) em termo simples e em termo quadrático, além dos níveis de governança corporativa (GC). O coeficiente da variável ENDTOTAL em termo simples apresenta significância estatística, ao contrário de sua forma quadrática (ENTOTAL ${ }^{2}$ ). Desse modo, verifica-se que uma redução do $\mathrm{Q}$ de Tobin à medida que o endividamento aumenta, num padrão linear, levando à rejeição da Hipótese 1C.

O modelo representado pela equação (3) apresentou $\mathrm{R}^{2}$-ajustado de 17,53 , levemente inferior aos observados para as equações (4) e (5). Isso indica que o modelo de regressão com o endividamento em termos simples e quadrático é menos adequado que os demais para explicar as variações no $Q$ de Tobin.

Os índices VIF apurados para as variáveis representativas do endividamento apresentaram valores próximos a 1 para as equações (1) e (2) e superiores a 10 para as variáveis ENDTOTAL e ENDTOTAL ${ }^{2}$, para a equação (3), o que indica a multicolinearidade nessas variáveis explicativas, resultado já esperado devido à operacionalização da variável ENDTOTAL $^{2}$. Quanto à variável GC, o teste VIF apresentou valor próximo a 1 para as três equações, indicando ausência de multicolinearidade. A estatística de Kolmogorov-Smirnov (KS) foi utilizada para testar a normalidade dos resíduos e, considerando os p-valores inferiores a 0,010, os resíduos são oriundos de uma distribuição não normal. A estatística de DurbinWatson foi analisada com o objetivo de identificar autocorrelação entre os resíduos e os valores apurados situaram abaixo do limite de 3,000.

\subsection{Variável dependente VOLATIL}

Os resultados das estimações dos parâmetros dos modelos das equações (4), (5) e (6) são apresentados na Tabela 3. A Hipótese 2 não foi rejeitada, em razão do efeito positivo do endividamento total no risco, conforme apurado em relação à equação (4). Quanto aos níveis de governança, seu efeito no desempenho se apresentou negativo e estatisticamente significativo ( $\mathrm{p}<0,010)$, levando à não rejeição da Hipótese 4 , para os três modelos. 
Tabela 3 2Ajuste dos modelos para a variável VOLATIL

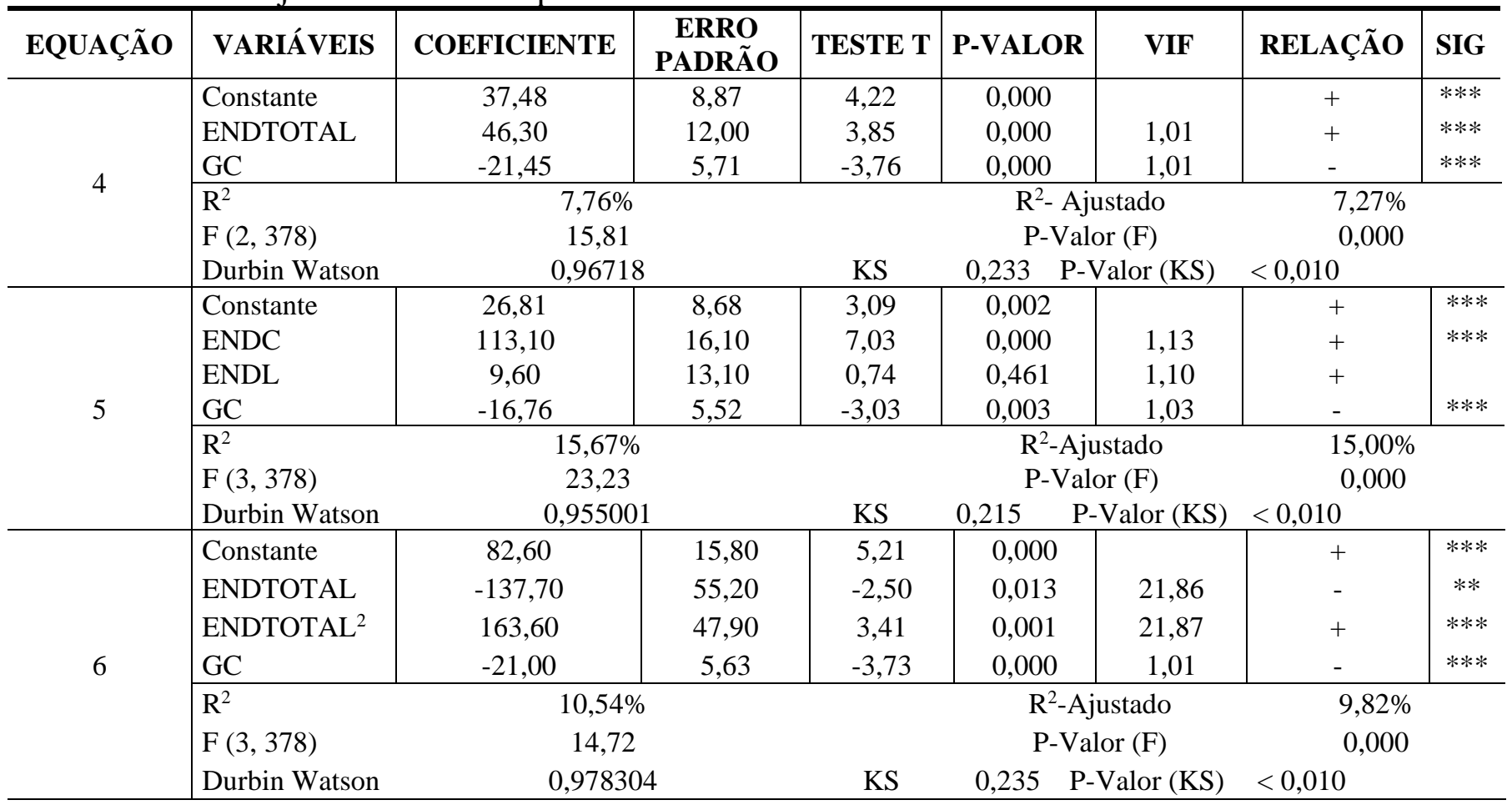

* significância a 10\%, ** significância a 5\% e *** significância a 1\%.

As variáveis de estrutura de capital foram utilizadas no modelo da equação (5) como variáveis explicativas da variação do risco. O indicador endividamento de curto prazo apresenta efeito positivo e estatisticamente significativo $(\mathrm{p}<0,010)$, com o risco da firma. Dessa forma, à medida que o endividamento de curto prazo aumenta, o risco também aumenta. O efeito do endividamento de longo prazo no risco da firma não apresenta significância estatística, resultado que leva à rejeição da Hipótese 2B.

O modelo representado pela equação (5) apresentou $\mathrm{R}^{2}$-Ajustado de $15,00 \%$, mais que o dobro do apurado para o modelo da equação (6) e quase o dobro do apurado para o modelo da equação (7). A estatística $\mathrm{F}$ e seu respectivo p-valor foram significativos para a amostra estudada, indicando que a porção de variância explicada pelo modelo é significativa. Os índices VIF apresentaram valores próximos a 1, o que indica ausência de multicolinearidade entre as variáveis explicativas.

A variável ENDTOTAL foi utilizada no modelo da equação (6) em termos simples e quadrático, assim como a variável GC. O coeficiente da variável ENDTOTAL apresenta sinal negativo e significância estatística $(\mathrm{p}<0,050)$, ao contrário de sua forma quadrática que apresenta sinal positivo e significância estatística a 1,00\%. Desse modo, verifica-se que o risco 
aumenta à medida que o endividamento total aumenta, resultado que leva à não rejeição da Hipótese 2C.

O modelo representado pela equação (6) apresentou $\mathrm{R}^{2}$-ajustado de $9,82 \%$, superior ao observado para a equação (4) e inferior ao observado para a equação (5), indicando que o modelo de regressão com o endividamento subdividido em longo e curto prazos é mais adequado que os demais para explicar as variações no risco da firma.

Os índices VIF apurados para as variáveis representativas do endividamento apresentaram valores próximos a 1 para as equações (4) e (5) e superiores a 20 para as variáveis ENDTOTAL e ENDTOTAL ${ }^{2}$, para a equação (6), o que indica multicolinearidade, resultado já esperado devido ao fato da variável ENDTOTAL ${ }^{2}$ ser mensurada como o ENDTOTAL em sua versão quadrática. Quanto à variável GC, o teste VIF apresentou valor próximo a 1 para as três equações, o que indica ausência de multicolinearidade. A estatística de Kolmogorov-Smirnov (KS) foi utilizada para testar a normalidade dos resíduos e, considerando os p-valores inferiores a 0,010, os resíduos são oriundos de uma distribuição não normal. A estatística de DurbinWatson foi analisada com o objetivo de identificar autocorrelação entre os resíduos e os valores apurados situaram abaixo do limite de 3,000.

\section{Apresentação e Discussão dos resultados}

Os resultados da estimação dos efeitos do endividamento total em termo simples no desempenho apontam para um incremento do desempenho em função da redução do endividamento total. $\mathrm{O}$ endividamento total em sua forma quadrática não exerce influência estatisticamente significativa, ao passo que o endividamento total em sua forma simples exerce influência negativa. Considerando o desdobramento do endividamento em suas dimensões de curto e de longo prazos, há, portanto, alinhamento com a teoria Pecking Order, desenvolvida por Myers \& Majluf (1984), e coerência com as pesquisas de Avelar et al. (2017), Corrêa, Basso e Nakamura (2013), Machado et al. (2015), Manoel, Santos e Moraes (2016), Mendes e Santos (2018) e Reis et al. (2017).

A análise do efeito do endividamento total, em sua forma simples, no risco da firma, permite a identificação de um incremento no risco à medida que o endividamento total aumenta. Esse resultado também foi apurado para os efeitos do endividamento total, em sua forma quadrática, no risco, mais que compensando os efeitos negativos do endividamento total em sua forma simples. Esse resultado é suportado pela teoria Static Trade-Off, de Myers (1984). Segundo Fama and French (2002), as firmas mais arriscadas são menos endividadas, mas, 
conforme Danis et al. (2014), a partir do momento em que houver um desajuste no endividamento, isso provocará o efeito negativo na lucratividade, ocasionando possivelmente maior risco de falência, com os custos associados a esse risco elevando a volatilidade das ações.

O endividamento de curto prazo exerce influência positiva no risco da firma, enquanto o endividamento de longo prazo não exerce influência estatisticamente significativa no risco. De acordo com Correia et al. (2018), à medida que as firmas lidam com maior endividamento de curto prazo, elas sinalizam para o mercado um aumento do risco de falência devido às obrigações próximas de vencimento, o que reflete diretamente na volatilidade das ações.

A relação entre o nível de governança e o desempenho foi estatisticamente significativa e positiva em todos os modelos, resultado em alinhamento com os obtidos nos estudos de Almeida et al. (2018), Catapan e Colauto (2014), Cunha (2017), Lima et al. (2015), Silva (2004) e Silveira (2002).

Os resultados da estimação dos modelos (4), (5) e (6) indicam uma relação negativa e estatisticamente significativa entre os níveis de governança e o indicador de risco volatilidade das ações, resultado semelhante ao obtido nas pesquisas de Alves (2010), Besarria et al. (2015) e Besarria e Silva (2017), que identificaram que as firmas listadas nos segmentos de governança corporativa da $[\mathrm{B}] 3$ apresentam menor risco. A adoção de boas práticas de governança corporativa possibilita aos investidores avaliarem o desempenho econômico financeiro com maior precisão, reduzindo a variação nos preços das ações da firma.

\section{Considerações finais}

Inicialmente estabeleceu-se como principal objetivo "identificar a influência da utilização das melhores práticas de governança corporativa, medidas pelos níveis de governança corporativa da $[\mathrm{B}] 3$, e da estrutura de capital, sobre o desempenho e o risco das firmas brasileiras de capital aberto listadas na [B]3, do setor da indústria manufatureira".

Ao analisar a influência das boas práticas de governança corporativa sobre o desempenho e o risco das firmas brasileiras listadas na $[\mathrm{B}] 3$, observou-se que as firmas da indústria manufatureira listadas nos níveis de governança corporativa tendem a apresentar maior desempenho no mercado de capitais e menor risco em relação às firmas do mercado tradicional. Os resultados indicam que as firmas que adotam as boas práticas de governança corporativa, como transparência, prestação de contas e responsabilidade corporativa, apresentam maior tendência de obterem resultados mais favoráveis em termos de desempenho no mercado de 
capitais. Isso provoca um efeito positivo na percepção e na avaliação dos investidores, o que redunda em maior valor da firma e menor risco para os investidores.

Quanto à influência da estrutura de capital sobre o desempenho, o modelo composto pelo endividamento decomposto em curto e longo prazo mostra-se mais adequado para explicar a variação do valor da firma ( $\mathrm{Q}$ de Tobin). O resultado mostrou que o endividamento total influencia positivamente o retorno para os acionistas até o nível ótimo de endividamento, a partir do qual passa a exercer influência negativa.

Foi constatado que o endividamento total em termos simples e quadrático foi mais adequado para explicar a volatilidade das ações do que apenas o endividamento em termo simples. Com o resultado encontrado verifica-se que o endividamento total influencia negativamente a volatilidade das ações até o nível ótimo de endividamento, quando passa a influenciar positivamente. Esses resultados sugerem uma tendência para a teoria Trade-Off, pois as firmas menos arriscadas conseguem contrair mais dívidas até o nível ótimo de endividamento, mas, a partir desse ponto, os riscos de falência decorridos do desajuste das dívidas provocam aumento do risco das firmas.

Quando decomposto o endividamento em curto e longo prazo, verifica-se que apenas o de curto prazo apresenta relação negativa com a volatilidade das ações. Tais resultados sugerem que quanto maiores as obrigações de curto prazo, maior é a percepção das possibilidades de falência da firma, o que consequentemente provoca um aumento do risco, indicando tendência à teoria Static Trade-Off.

Como limitações da pesquisa tem-se que foi verificada a autocorrelação dos resíduos nos modelos, pelo teste de Durbin-Watson, e que a amostra estudada não segue uma distribuição normal de probabilidade, pelo teste de resíduos de Kolmogorov-Smirnov, o que não invalida os resultados da pesquisa, mas não permite generalizações além da amostra e do período analisado.

Apesar de os níveis de governança corporativa da [B]3 serem amplamente utilizados nas pesquisas nacionais, eles são vistos apenas no Brasil. Isso limita a comparação com pesquisas internacionais e também a comparação dos resultados de firmas no mercado tradicional com as de segmentos diferenciados de governança corporativa, dada a quantidade limitada de firmas listadas na $[\mathrm{B}] 3$.

Considerando os resultados do estudo, indicam-se novos estudos acerca da relação entre governança corporativa, estrutura de capital e desempenho, com a finalidade de aprimorar o modelo e ampliar os conhecimentos, principalmente com a inclusão de novas variáveis nos modelos que possam ser condicionantes do desempenho e estar relacionados a estrutura de 
capital como: crescimento do produto interno bruto e a taxa de juros e de câmbio do país e tamanho e tangibilidade do ativo, oportunidades de crescimento e internacionalização da firma.

\section{Referências}

Almeida, F. T., Parente, P. H. N., Luca, M. M. M., \& Vasconcelos, A. C. (2018). Governança corporativa e desempenho empresarial: uma análise nas empresas brasileiras de construção e engenharia. Gestão \& Regionalidade, 34(100), pp. 110-126.

Alves, E. S. (2010). Governança corporativa, desempenho e risco no Brasil. (Dissertação de Mestrado). Universidade de Brasília, Brasília, Brasil.

Araújo, J. G., Confessor, K. L. A., Santos, J. F. D., Oliveira, M. R. G., \& Prazeres, R. V. D. (2017). A estrutura de capital e a governança: análise dos conselhos de administração e estrutura de propriedade nas empresas listadas no IBRX-100. Revista de Gestão, Finanças e Contabilidade, 7(2), pp. 121-140.

Artikis., P. G., \& Nifora, G. (2011). The industry effect on the relationship between leverage and return. Urasian Business Review, 1(2), pp. 125-145.

Avelar, E. A., Cavalcanti, J. M. M., Pereira, H. R., \& Boina, T. M. (2017). Determinantes da estrutura de capital: um estudo sobre empresas mineiras de capital fechado. Revista Evidenciação Contábil \& Finanças, 5(2), pp. 23-39.

Bernardino, F. F. M., Peixoto, F. M., \& Ferreira, R. N. (2014). Governança corporativa e valor da firma: um estudo de empresas brasileiras do setor elétrico. Revista Eletrônica de Ciência Administrativa, 13(2), pp. 185-202.

Besarria, C. N., Paula, A., Araújo, B. S., Alves, J. N., Almeida, F. F., \& Monteiro, V. S. (2015) A qualidade das informações prestadas pelas empresas reduz os riscos de investimento? Uma análise empírica para os diferentes níveis de governança corporativa das empresas brasileiras. RACE: Revista de Administração, Contabilidade e Economia, 14(1), pp. 11-38.

Besarria, C. N., \& Silva, H. S. (2017). A efetividade da governança corporativa sobre o risco dos ativos da BM\&FBovespa. RACE: Revista de Administração, Contabilidade e Economia, 16(3), pp. 933-956.

Brealey, R., Myers, S. C., \& Allen, F. Princípios de finanças empresariais. 8. ed. São Paulo: McGraw-Hill, 2007.

[B]3. Níveis diferenciados de governança corporativa. Disponível em: <http://www.bmfbovespa.com.br>. Acessado em: 04 abr. 2018.

Catapan, A., \& Colauto, R. D. (2014). Governança corporativa: uma análise de sua relação com desempenho econômico-financeiro de empresas cotadas no Brasil nos anos de 20102012. Contaduría y Administración, 59(3), pp. 137-164. 
Cicogna, M. P. V., Toneto, J. R., \& Valle, M. R. (2007). O impacto da adesão a padrões mais elevados de governança sobre o financiamento empresarial. Revista de Administração RAUSP, 42(1), pp. 52-63.

Corrêa, C. A., Basso, L. F. C., \& Nakamura, W. T. (2013). A estrutura de capital das maiores empresas brasileiras: análise empírica das teorias de pecking order e trade-off, usando panel data. Revista de Administração Mackenzie, 14(4), pp. 106-133.

Correia, T. S., Silva, M. N. F., \& Martins, O. S. (2018). Indicadores de assimetria de informação e estrutura de capital das empresas abertas no Brasil. Revista Evidenciação Contábil \& Finanças, 6(1), pp. 24-42.

Cunha. M. A. M. (2017). Relação entre níveis de governança corporativa e criação de valor para o acionista. XX SEMEAD Seminários em Administração, São Paulo, SP, Brasil, 20. Recuperado de http://login.semead.com.br/20semead/anais/arquivos/1272.pdf.

Danis, A., Rettl, D. A., \& Whited, T. M. (2014). Refinancing, profitability and capital structure. Journal of Financial Economics, 114(3), pp. 424-443.

Durand, D. (1952). Cost of debt and equity funds for business: trends and problems in measurement. Proceedings of the Conference on Research in Business Finance, New York, New York, USA. Recuperado de http://www.nber.org/chapters/c4790.pdf.

Fama, E. F., \& French, K. R. (2002). Testing trade-off and pecking order predictions about dividends and debt. The Review of Financial Studies, 15(1), pp. 1-33.

Fama, E. F., \& French, K. R. (2012). Capital structure choices. Critical Finance Review, 1(), pp. 59-101.

Famá, R., \& Barros, L. A. (2000). Q de Tobin e seu uso em finanças: aspectos metodológicos e conceituais. Cadernos de Pesquisa em Administração, 7(4), pp. 27-43.

Fonseca, C. V. C., Silveira, R. L. F., \& Hiratuka, C. (2016). A relação entre a governança corporativa e a estrutura de capital das empresas brasileiras no período 2000-2013. Enfoque Reflexão Contábil, 35(2), pp. 35-52.

Frank, M. Z., \& Goyal, V. K. (2003). Testing the pecking order theory of capital structure. Journal of Financial Economics, 67(), pp. 217-248.

Gonçalves, C. A., Dias, A. T., De-Carvalho, J. P., \& Martins, H. C. (2014). Grupos estratégicos, diversificação, perfil do endividamento e seus efeitos no desempenho da firma. XXXVIII Enanpad. Rio de Janeiro, RJ, Brasil, 38.

Koerniadi, H., Krishnamurti, C., \& Tourani-Rad, A. (2014). Corporate governance and risktaking in New Zealand. Australian Journal of Management, 39(2), pp. 227-245.

Lara, J. E., \& Mesquita, J. M. C. (2008). Estrutura de capital e rentabilidade: análise do desempenho de empresas brasileiras no período pós-Plano Real. Revista Contabilidade Vista e Revista, 19(2), pp. 15-33. 
Leites, E. T., \& Zani, J. (2008). A influência dos juros sobre o capital próprio na formação da estrutura de capital. SEGET - Simpósio de Excelência em Gestão e Tecnologia, Resende, RJ, Brasil, $5 . \quad$ Recuperado de http://www.aedb.br/seget/arquivos/artigos08/249_JSCPSEGeT.pdf.

Lima, S. H. O., Oliveira, F. D., Cabral, A. C. A., Santos, S. M. D., \& Pessoa, M. N. M. (2015). Governança corporativa e desempenho econômico: uma análise dos indicadores de desempenho entre os três níveis do mercado diferenciado da BM\&FBovespa. Revista de Gestão, 22(2), pp. 1-18.

Louzada, L. C, Oliveira, J. P. D. D, Silva, A. F. P. D., \& Gonçalves, M. A. (2016). Análise comparativa entre os indicadores econômico-financeiros aplicados às indústrias manufatureiras listadas na BOVESPA. Revista Eletrônica do Alto Vale do Itajaí. REAVI, 5(7), pp.17-36.

Machado, L. K. C., Prado, J. W., Vieira, K. C., Antonialli, L. M., \& Santos, A. C. D. (2015). A relevância da estrutura de capital no desempenho das firmas: uma análise multivariada das empresas brasileiras de capital aberto. Revista de Educação e Pesquisa em Contabilidade, 9(4), pp. 397-414.

Malacrida, M. J. C., \& Yamamoto, M. M. (2006). Governança corporativa: nível de evidenciação das informações e sua relação com a volatilidade das ações do Ibovespa. Revista Contabilidade \& Finanças - USP, 17(), pp. 65-79.

Manoel, A. A. S., Santos, D. F. L., \& Moraes, M. B. C. (2016). Determinantes do endividamento na indústria sucroenergética brasileira: análise a partir das teorias de estrutura de capital. Organizações Rurais \& Agroindustriais, 18(2), pp. 140-153.

Martins, E., Gelbeke, E. R., Santos, A. dos., \& Iudícibus, S. Manual de Contabilidade Societária. 2. ed. São Paulo: Atlas, 2013.

Medeiros, O. R., \& Daher, C. E. (2008). Testando teorias alternativas sobre a estrutura de capital nas empresas brasileiras. Revista de Administração Contemporânea (RAC), 12(1), pp. 177-199.

Mendes, G. S., \& Santos, D. F. L. (2018). Estrutura de capital, dinâmica da indústria e desempenho financeiro: a construção de um modelo de análise das firmas no Brasil. Revista Organizações em Contexto, 14(27), pp. 271-303.

Modigliani, F., \& Miller, M. H. (1958). The cost of capital, corporation finance and the theory of investment. The American Economic Review, 48(3), pp. 261-297.

Modigliani, F., \& Miller, M. H. (1963). Corporate income taxes and the cost of capital: a correction. The American Economic Review, 53(3), pp. 433-443.

Myers, S. C. (1984). The capital structure puzzle. The Journal of Finance, 39(3), pp. 574-592.

Myers, S. C. (2001). Capital structure. The Journal of Economic Perspectives, 15(2), pp. 81102. 
Myers, S. C., \& Majluf, N. S. (1984). Corporate financing and investment decisions when firms have information that investors do not have. Journal of Financial Economics, 13(2), pp. 187-221.

Pamplona, E., Magro, C. B. D, \& Silva, T. P. (2017). A estrutura de capital e o desempenho econômico de empresas familiares do Brasil e de Portugal. Revista de Gestão dos Países de Língua Portuguesa, 16(2), pp.38-54.

Pinheiro, B. G., Vasconcelos, A. C., Luca, M. M. M., \& Crisóstomo, V. L. (2017). Estrutura de capital e governança corporativa nas empresas listadas na BM\&FBovespa. Revista de Educação e Pesquisa em Contabilidade, 11(4), pp. 451-466.

Reis, R. T., Campos, A. L. S., \& Pasquini, E. S. (2017). A influência dos determinantes da estrutura de capital conforme o estágio do ciclo de vida das empresas brasileiras. Revista de Gestão, Finanças e Contabilidade, 7(3), pp. 127-142.

Ripamonti, A., \& Kayo, E. K. (2016). Corporate governance and capital structure in Brazil: stock, bonds and substitution. Revista de Administração Mackenzie, 17(5), pp. 85-109.

Rogers P., Securato, J. P., Ribeiro, \& K. C. S. (2008). Governança corporativa, custo de capital e retorno do investimento no brasil. Revista de Gestão USP, 15(1), pp. 61-77.

Shleifer, A., \& Vishny, R. W. (1997). A survey of corporate governance. Journal of Finance, 52(2), pp. 737-783.

Silva, A. L. C. da (2004). Governança corporativa, valor, alavancagem e política de dividendos das empresas brasileiras. Revista de Administração, 39(4), pp. 348-361.

Silva, A, L. C. da, \& Leal, R. P. C. (2005). Corporate governance index, firm valuation and performance in Brazil. Revista Brasileira de Finanças, 3(1), pp. 1-18.

Silva, E. D. S., Santos, J. F. D., \& Nakamura, W. T. (2018). A heterogeneidade da estrutura de capital das empresas dos países desenvolvidos - G7: uma Análise quantílica. Gestão \& Regionalidade, 34(100), pp. 4-21.

Silva, J. P., \& Silva, D. C. (2017). Análise da relação entre estrutura de capital, crescimento, lucratividade e valor de mercado das companhias brasileiras de capital aberto. Revista Mineira de Contabilidade, 18(1), pp. 15-25.

Silveira, A. De M. (2002). Governança corporativa, desempenho e valor da empresa no Brasil. (Dissertação de Mestrado). Faculdade de Economia, Administração e Contabilidade, Universidade Federal de São Paulo, São Paulo, Brasil.

Silveira, A. De M., Perobelli, F. F. C., \& Barros, L. A. B. C. (2008). Governança Corporativa e os determinantes da estrutura de capital: evidências empíricas no Brasil. Revista de Administração Contemporânea (RAC), 12(3), pp. 763-788.

Vieira, K. M., Velasquez, M. D., Losekann, V. L., \& Ceretta, P. S. (2011). A influência da governança corporativa no desempenho e na estrutura de capital das empresas listadas na Bovespa. Revista Universo Contábil, 7(1), pp. 49-67. 